\title{
Future perspectives on technological development ${ }^{1}$
}

\author{
by Ross S. Whaley ${ }^{2}$ \\ Keynote Address, IUFRO XX World Congress, Tampere, Finland, 10 August 1995
}

The recurring theme of the keynote presentations, Future Perspectives on Caring for Forests: Research in a Changing World, should by now be thoroughly familiar to all of us. President Saleh in his opening comments stressed caring for the forests. I want to focus my comments on the second part of our theme - change and its implications for research.

I will try to make the case that the need for technological change in the next couple of decades will be as great as any time in the past century. This pressure for technological development will be fueled by changes in the socioeconomic context, both domestic and international, in which the forestry enterprise operates. Further, the key to solving many of the environmental concerns facing forestry will be resolved by improving technology, not by retreating to an earlier technology as often proposed by some well-intentioned environmentalists. Indeed, our approach to research and technological innovation will fundamentally change.

I will organize my presentation around three propositions:

I. The period from 1990-95 brought about a change in global attitudes about forests, forestry and forest products manufacture unprecedented in the past half century.

II. Signals abound that during the next few decades forestry will be practiced under social and economic conditions for raw materials and products which are significantly different than today.

III. While forest industry success in the past couple of decades was determined mostly by marketing, financial and political skill, in future it will be influenced to a greater extent by technological adaptation.

\section{Proposition I}

The period from 1990 to 1995 brought about a change in global attitudes about forests, forestry, and forest products manufacture unprecedented in the past half century.

While there have always been changes in the expectations for our forests: economic development at one time, materials for a war effort the next, pressures for maintaining aesthetic opportunities or biological integrity during another period, the past half decade has coalesced these divergent interests into a more inclusive process, with more comprehensive emerging policies than ever before in the history of forestry. This more complex, more comprehensive approach is subsumed, perhaps poorly, under the term "sustainability." It is comprehensive in several ways heretofore not seen in forest policy development: a. it has both domestic and international dimensions;

b. it considers both short-run needs and long-run potential;

'Keynote address presented at the XX IUFRO World Congress. This address is also published in the Congress Report of the IUFRO Congress.

${ }^{2}$ President, SUNY College of Environmental Science and Forestry, Syracuse, NY. c. it calls for simultaneous consideration of economic, environmental and community improvement objectives;

d. it involves a policy development and implementation framework which brings people together in a negotiating setting rather than a winner-take-all adversarial setting.

Some might argue that this attention to sustainability is another political fad which will pass as fast as it arrived. I do not think so.

There is considerable evidence that this is likely to be more than a short-lived, international, political ploy to obfuscate serious land use conflicts:

- Consider the large number of heads of state at the UNCED conference in 1992.

- Consider the seriousness with which many countries or groups of countries have taken the follow-up responsibilities to UNCED as witnessed by such activities as the "Helsinki process" and "Montreal process" aimed at developing internationally agreed upon Principles and Criteria for Sustainable Forestry, or the attention to the same concerns by the tropical countries.

- In the United States of America there has been a re-evaluation of the role of state-owned forest lands, and the forest products industry is making major changes in the way it manages forests.

This is only a partial list of activities which suggest a change in attitudes about forests and forestry by both government and private enterprise.

Even with these changes, some people are convinced that we have reached the carrying capacity of the globe and further economic development is inherently not sustainable. They conclude that economic growth and the technological advances which have occurred are primarily responsible for global warming, acid rain, deforestation, desertification, soil erosion, polluted water, and therefore only stopping economic growth, curtailing, technological change, and reducing consumption by the countries of North America, western Europe and Japan will ultimately be sustainable. When proposed by the academic community, this view is often referred to by terms such as "a steady state economy." While there might be some conceptual attractiveness to this idea, this is an abstraction which eludes attainment. The most realistic alternative is a commitment to sustainable development, whether or not it is ultimately attainable if world population approaches 10 or 11 billion people. The concept of sustainable development is easily understood even if the implementation is difficult. It is, in its most simple form, "economic activities thoughtfully and intelligently managed in such a way that they do not destroy or significantly impov- 
erish the natural support systems on which they or other economic activities depend" (conversation with Jack Manno).

I conclude that the concept of sustainable development is here to stay, whether called by that name or something else.

\section{Proposition II}

Signals abound that during the next two decades sustainable forestry will have to be practiced under social and economic conditions for raw materials and products which are significantly different than today.

While there are dozens of forces which will ultimately and irrevocably reshape the societies in which we live, I would like to mention the four which I think will have more impact on the forestry enterprise than any of the others. In examining future trends, I have chosen to look forward approximately two to three decades. I pick that period as one particularly relevant to forestry researchers. Several years ago the research branch of the U.S. Forest Service did a study of the economic contributions of its research. Among other findings they discovered that from the inception of a researchable idea to the implementation of a research result often took as long as 25 years and averaged about 12 . If those numbers have any applicability to the research community worldwide, new research ideas which we take away from the IUFRO Congress may well not be implemented until the second decade of the 21 st century.

\section{Population}

It is unnecessary to dwell on population growth to this audience which is more aware than most of the potential impacts of demographic change on forest products demand and pressures on resources extraction of all kinds. And Mr. Bennett at yesterday's keynote reminded us again of the impact of population growth on land use. However, I would like to emphasize some characteristics of the changing demographic scene which may give clues to the particular kinds of research which will be needed to respond to the changing demographic scene.

Though global population growth rates have declined during the past couple of decades, the actual number of people added to the world every year is about 90 million people the equivalent of another United States of America every two and a half years, another India every nine years, or another China every 12 years. As we look forward to the next 25 years, over one-third of the population growth will be in five countries: China, India, Brazil, Mexico, and Indonesia. The pressures on resources will increase substantially and it will be distributed quite unevenly.

Another point which is likely to influence forest products demand also mentioned by $\mathrm{Mr}$. Bennett is the increased urbanization of the world's population. In 1990 there were 13 cities worldwide with populations which exceeded 10 million people. Within the next 15 years, there will probably be 26 , and by the year 2025, 60 percent of the world's population is likely to dwell in urban areas.

Even more significant from the standpoint of forest products demand is that the total world economy is growing faster than population growth. While population doubled between 1950 and 1990. the global economy increased fivefold. World Bank estimates indicate that within the next 30 years average per capita income worldwide could reach the level of the richest one-fifth of the world in 1990.

Economists and demographers will certainly differ in their estimates of economic and population growth, but on average world markets will grow, economies will grow, and the conflicts about economic growth and maintaining the highest quality living environment will increase.

\section{International Trade}

Though some countries or sectors within countries will be strong advocates for expanded international trade and others will be more protectionists, there is an irreversible trend toward expanding trade. Governments prone to protectionist policies will ultimately be thwarted by the increasingly powerful transnational corporations who will benefit from free trade. Even the concept of balance of trade becomes confounded when more than a third of global trade is intracorporate. For example, firm A in one country sells to firm B, a subsidiary, in another country. This potential increase in movement of resources and products in a global market seems to add emphasis to the need to consider how to accomplish expanding economic growth in a sustainable manner, while at the same time making sustainable development more difficult to achieve because different countries will have different attitudes regarding the importance of sustainability.

A major result of increasing international trade and the redistribution of investment among more countries will be the emergence of a global middle class. The emergence of this middle class will both result from growing international trade and also be the cause for its further expansion. Unfortunately there will be some parts of the world which may not participate in this overall economic gain.

\section{Changes in Manufacturing Processes}

Not only will markets be larger, but they will be for a variety of products unprecedented in times past when efficient production, at least in the developed countries, was based on large factories with endless assembly lines producing a homogeneous product. Mass production worked when the products coming off the end of the assembly line were essentially all the same. There were cost savings making it possible in the developed nations for many people to have a car. a house, an abundance of clothing, as long as the car, house and clothes were quite similar to those of their neighbors. The advent of the application of computers to both the design and manufacturing process has improved the efficiency of smaller manufacturing firms and has allowed larger firms to increase the variety of products produced. Heidi and Alvin Toffler describe this as the "demassifying of society". The impacts of this on decentralizing manufacturing, reducing capital intensity. allowing manufacturing for specialized products in remote locations, is an interesting investigation in and of itself, and worthy or a more thorough discussion.

For today I want to emphasize that the forest products industry has lagged behind others in product diversity. In my country, for example, almost all residential construction uses the same wood materials - boards nominally 2 " thick. 4 " wide and $8^{\prime}$ long and sheets of plywood or particle board $4^{\prime}$ wide and $8^{\prime}$ long. Other countries have their standard products. which though efficient to produce, may not keep pace with manufacturing changes demanded by society. As I will point out later. 
that will have to change in the not-too-distant future if wood products are to continue to play a major role in residential construction.

\section{Changing Energy Demand}

During the 1970 s, when oil was approaching $\$ 50$ per barrel on the international market, considerable attention was paid to improving energy conservation. Western Europe and Japan were particular leaders in improving energy efficiency in manufacturing and transportation. The rigor with which industrial nations approached energy conservation declined as oil prices approached $\$ 17$ per barrel. The industrial nations of North American and Europe appear to be more sanguine about energy costs.

But what is on the horizon? The steady increase in oil consumption by the emerging economies of Asia accounts for $70 \%$ of the new global demand for petroleum. At its current growth rate of $5 \%$ per year, "the Asian Pacific region will outstrip North America in energy consumption by 1999. Meanwhile consumption in the US, Europe and Japan has crept back to its highest level since 1979" (Fortune, March 20 1995). Joe Coates, an American futurist, looking at the year 2025 predicts energy consumption per capita in the advanced nations will only be $66 \%$ as much as in 1990 . But during the same period in the rest of the world, energy consumption will increase by $160 \%$. Energy costs (which triggered the two worst recessions since 1945) are prone to increase sharply when demand pinches supply.

To summarize the second proposition, two decades hence we all will live in a world:

- in which the population is $45 \%$ larger and considerably more urbanized,

- we will see the emergence of a global middle class with some unfortunate pockets of poverty.

- manufactured products will be more diverse, produced in smaller plants, and traded internationally more aggressively than today, and

- energy supply will be a nagging problem.

\section{Proposition III}

While forest products industry success in the past couple of decades has been determined mostly by marketing, financial and political skill, in the next two decades success will be influenced to a greater extent by technological adaptation.

If two decades hence we live in a world in which demand for wood products surpasses our current projections, and we are trying to increase our dependence on renewable raw materials in place of non-renewable, but at the same time we are committed to forests which are biologically diverse and ecologically healthy, then we indeed have forecasted a problem. The only potential for meeting these apparently incongruous objectives will depend upon research and its ultimate product, technological change. During this period of time, technological change will be seen as the only solution for maintaining ecological integrity rather than the cause of ecological decline.

There is insufficient time during this presentation to lay out a research agenda for sustainable forestry under increasing demand for forest products. The details can be more effectively discussed in the subplenary and division meetings when you the scientists, exchange your ideas on research needs. There are, however, four broad areas in which research and technological change will be essential to meet the challenge that we are facing.

\section{Product Development}

Most research in wood products for construction has started with traditional solid wood materials and attempted to make them more competitive with alternative materials. How do we make wood dimensionally more stable, fire retardent, stronger, easier to fasten, easier to shape in order to maintain the competitive edge against other materials trying to find markets in construction? We looked for ways to use smaller trees or heretofore less desirable species in our traditional construction materials. The idea that other materials might be complementary rather than competitive was not the focus of our attention. The potential of grinding up wood and breaking it down chemically should now go well beyond its use for paper and look for totally new uses for wood. The inherent renewability of wood and its high fiber to weight ratio suggests combining wood with materials which are more water and decay resistant, into composites which can be easily shaped, can lead to uses of wood which range from inexpensive factory built modular homes to biodegradable backing for computer chips. Ultimately these new materials might be less demanding on particular species, more effectively use fast-growing plantation grown trees, have greater longevity in use, and in the case of combinations with plastics, increase the opportunity for recycling a product for which waste disposal is becoming a problem.

\section{Biomass Farms}

If there is merit in using the basic components of a tree in reconstituted form rather than simply sawing a tree into lumber, then the potential of intensive biomass farms instead of natural forests offers considerable opportunities for both construction material as well as energy. Research on this is currently being done worldwide, but the beginning is only in sight. The potentials for biotechnology research for trees which are less demanding on site quality or moisture and are more tolerant to disease and insects is much greater in plantations than when the principle wood source is natural forests which are inherently more complex to manage. This type of forest management is not a substitute for our managed natural forests, but a complement which would increase our options for maintaining diversity and ecological integrity in natural forests.

\section{Industrial Ecology}

The manufacturing sector is learning from our understanding of ecological systems to design processes with a more thorough systems approach. This involves more imaginative ways of viewing raw materials whereby every component of the material is viewed as a potential product rather than some of it a waste material. Industrial ecology has included broader views of energy use and material conservation by taking a life cycle analysis of process and products. It results in collaboration between manufacturing processes which have heretofore been ignored. The excitement for industrial ecology not only stems from its potential in energy and raw material conservation, but the firms that have approached it with conviction and imagination have generally increased profits. To date, the forest products firms and forestry in general, 
with a few exceptions, have been followers not leaders in carefully examining industrial ecology.

Industrial ecology, biomass farming or product development are all aimed at increasing useful products while reducing the pressures on natural forests and the consumption of energy.

\section{Ecosystem Management}

As important as technological innovation will be the maintenance of healthy ecosystems, it is important to end with an observation on the overarching theme of this Congress, "caring for forests." With the move to a more comprehensive goal for forest management that goes beyond the objective of simply sustained yield of a product or combination of products to a more demanding goal of sustaining ecological processes, considerable research is needed in refining an operational vocabulary and a set of objectives for ecosystem management. With a long history of developing the concepts of sustained yield, we know how to define our products whether timber, water or recreation. We know how to mea- sure it in cubic meters or board feet of lumber or in acre feet of water or user days of recreation. We have developed concepts like non-declining even flow. But for those more involved in policy, the concept of ecosystem integrity is a more difficult one to achieve. What should we measure? How do I know when I have achieved it? When is it compatible with other goals of forest management? When is it not compatible? The balancing of economic, environmental and community objectives will be difficult until we can adequately communicate the goals and the tradeoffs.

Mr. President and Delegates, the challenges for forestry over the next couple of decades will be greater than ever before. Because the scientific talent is greater, and the public awareness sharpened, we will meet that challenge in ways unimagined even in 1995. I am excited about that world in which people are slightly better clothed, fed and housed than they are today, and they are still looking at forests which are ecologically more diverse and healthy than in their parents' time. 